\title{
Is It Time for a "Me-Too" Movement Against Attitudes Towards Women Suffering from Nongynecological Malignancies?
}

\author{
Reut Shashar ${ }^{1} \cdot$ Gilad E. Amiel $^{1}$
}

Accepted: 20 September 2021 / Published online: 22 September 2021

(c) American Association for Cancer Education 2021

\section{Introduction}

When considering cancer in women, we are accustomed to thinking of "female" malignancies—diseases such as breast and gynecological cancers, which affect mostly women. It is about time to discuss female aspects of cancers that are not categorized as diseases uniquely of women. Moreover, we must address these issues and attempt to minimize their impact on different aspects of a patient's femininity. Understanding and implementing these unique features of taking care of female oncology patients should become an integral part of our role as cancer physicians.

Malignancies such as breast and gynecological cancers are known as "women's diseases." They attack female organs, which have biological, functional, and sociological roles in defining women as women. In confronting such illness, women can understandably face a threat to the core of their femininity - their body image, fertility, childbearing, and sexuality all can be affected by the disease. Oncological and surgical treatments for these so-called women's cancers are sensitive to this: they focus not only on defeating the disease but also on protecting the patient from features of the illness and its therapy that can damage her identity as a woman.

In women with breast cancer, for example, breast preservation is usually part of the medical treatment, even though the breast may have no lactating role in these patients. Women who undergo mastectomy are routinely offered breast reconstruction in the understanding that the female breast can be central to femininity, that mastectomy can therefore cause disability, and that addressing the

Gilad E. Amiel

giladamiel@gmail.com

Reut Shashar

reutshashar@gmail.com

1 Department of Urology, RAMBAM Healthcare Campus, Haifa, Israel psychological and emotional aspects of diseases that harm the female organs is part of the physician's task. In cervical cancer, the patient's childbearing status is an important consideration in the choice of treatment. Women with ovarian cancer, who enter surgical menopause because of ovarian resection, are offered hormone replacement therapy and fertility preservation. Gynecologists understand that removing a female organ that plays a hormonal or a functional role can result in a disability that requires treatment.

It is not only the medical staff that supports these women. There is a wealth of support systems provided in the community for "female cancers" survivors, since these cancers are recognized as potentially harmful to women's body image and function. Many support systems are based on empowerment. Even though these diseases can damage a woman's femininity, there are many established tools to deal with them, to mourn what is taken away, and to resolve the challenges they bring.

\section{The Problem}

Unfortunately, the same cannot be stated for cancers that are not classified as uniquely "female." Here, insufficient attention is given to female patients and to their specific disease characteristics. This is at its worst in malignancies categorized as predominantly "male" diseases, such as urological and lung cancers. Baggio and her coworkers [1], describing gender differences in various types of cancer, state that there is inadequate focus on women patients in cancer research. Gender differences are seen, for example, in chemotherapy-related toxicity and in sensitivity to pain and pain relief medications in cancer patients. In colon cancer, women are older than men at diagnosis and are diagnosed at more advanced disease stages. In lung cancer, nonsmoking women are at higher risk than nonsmoking men; they live longer than men with this cancer, regardless of type of therapy and stage of diagnosis [1]. In bladder cancer, women 
are diagnosed at later stages and have worse prognoses [2]. Colon and urological malignancies are especially relevant because both of these systems are anatomically close to the female reproductive structures. These latter cancers and their common treatment options can therefore involve the female organs [3] and with them, women's health and quality of life.

Cancer illness impairs quality of life in all patients, but the biological, psychological, and sociological differences between men and women mean that it may do so differently by sex. Urological and gastrointestinal malignancies influence organs that are not uniquely female but are very different in their anatomy, physiology, and pathology in men versus women. The workup and therapy of these diseases can involve intimate organs, can cause sexual dysfunction, and can harm body image, but because they are not perceived as "female" malignancies, issues unique to women are not generally considered during treatment.

Very little has been published, or appears in textbooks, on the impact of such cancers on women's femininity, body image, or well-being as women. In colon cancer, proctocolectomy in women is associated with sexual dysfunction without any concomitant change in sexual desire [4]. Women who receive radiation therapy for rectal cancer are at increased risk of dyspareunia and vaginal dryness [5]. In bladder cancer, non-muscle-invasive bladder cancer can affect sexual function in both men and women [6]. Sexual dysfunction is prevalent in women who undergo radical cystectomy, from decreases in orgasm and lubrication to low libido and dyspareunia. Surgical modifications during surgery can help counter this, but they are undertaken only by surgeons who understand their importance [7]. Bladder cancer patients are also at higher risk for depression and anxiety [8]. This is not expressed only in later stages of the disease: even during standard examination for bladder cancer, female patients who undergo cystoscopy as part of the diagnosis and follow-up are at higher risk for anxiety due to the test than are male patients [9]. In marked contrast to the "female" malignancies, there are virtually no support systems for these other cancers that specifically address women.

\section{Raising Awareness}

The recognized "female" malignancies are not the only cancers that affect women, nor are they the only cancers that impact a patient's femininity and quality of life. In the same way that breast surgeons and gynecologists understand how the disease impacts their female patients and how to help them, physicians who treat women for other malignancies should learn how the ailments they treat can influence female patients and their femininity. Dedicated emotional counseling, support groups, and women empowerment should be offered to all women with cancer, not exclusively to those with "female" malignancies. Women with colon and bladder cancers should be screened for problems that include poor body image, depression, anxiety, and impaired sexual function; they should be offered support specifically tailored for them along with their medical treatment, i.e., management designed for the different biology of these cancers in women. In cancers where women are a minority of patients, even greater effort should be made to understand the unique aspects of their illness. With men constituting the majority of patients who suffer certain cancers, and with many male physicians treating those cancers, it is easy to overlook the specific needs of female patients. A first step would be to raise awareness about women's needs among caregivers. Further research into the quality of life of women with "nonfemale" malignancies and how to support them is required.

\section{References}

1. Baggio G, Corsini A, Floreani A, Giannini S, Zagonel V (2013) Gender medicine: a task for the third millennium. Clin Chem Lab Med 51:713-727. https://doi.org/10.1515/cclm-2012-0849

2. Madeb R, Messing EM (2004) Gender, racial and age differences in bladder cancer incidence and mortality. Urol Oncol Semin Orig Investig 22:86-92. https://doi.org/10.1016/S1078-1439(03) 00139-X

3. Djaladat H, Bruins HM, Miranda G, Cai J, Skinner EC, Daneshmand S (2012) Reproductive organ involvement in female patients undergoing radical cystectomy for urothelial bladder cancer. $\mathrm{J}$ Urol 188:2134-2138. https://doi.org/10.1016/j.juro.2012.08.024

4. Bambrick M, Fazio VW, Hull TL, Pucel G (1996) Sexual function following restorative proctocolectomy in women. Dis Colon Rectum 39:610-614. https://doi.org/10.1007/BF02056936

5. Bruheim K, Tveit KM, Skovlund E, Balteskard L, Carlsen E, Fosså SD, Guren MG (2010) Sexual function in females after radiotherapy for rectal cancer. Acta Oncol 49:826-832. https:// doi.org/10.3109/0284186X.2010.486411

6. Kowalkowski MA, Chandrashekar A, Amiel GE, Lerner SP, Wittmann DA, Latini DM, Goltz HH (2014) Examining sexual dysfunction in non-muscle-invasive bladder cancer: results of crosssectional mixed-methods research. Sex Med 2:141-151. https:// doi.org/10.1002/sm2.24

7. Zippe CD, Raina R, Shah AD, Massanyi EZ, Agarwal A, Ulchaker J, Jones S, Klein E (2004) Female sexual dysfunction after radical cystectomy: a new outcome measure. Urology 63:1153-1157. https://doi.org/10.1016/j.urology.2003.12.034

8. Vartolomei L, Vartolomei MD, Shariat SF (2020) Bladder cancer: depression, anxiety, and suicidality among the highest-risk oncology patients. Eur Urol Focus 6:1158-1161. https://doi.org/ 10.1016/j.euf.2019.10.008

9. Ellis G, Pridgeon S, Lamb BW, Awsare NS, Osaghae S, Smith SG, McNicholas TA, Green JSA (2015) Psychological distress in out-patients undergoing flexible cystoscopy for the investigation of bladder cancer. J Clin Urol 8:196-201. https://doi.org/10.1177/ 2051415814551821

Publisher's Note Springer Nature remains neutral with regard to jurisdictional claims in published maps and institutional affiliations. 